\title{
Follow up study eight years after diagnosis of sexual abuse
}

T E Frothingham, C J Hobbs, J M Wynne, L Yee, A Goyal, D J Wadsworth

\begin{abstract}
Aim-To study the outcome over an eight year period of children determined by paediatricians in 1989 as definitely or probably sexually abused.

Method-Information was obtained on 140 of 148 children diagnosed in 1989 when aged 7 or less. Sources were hospital medical records and school health records. School health records of a comparison group of 83 children were also examined.

Results-A variety of problematic characteristics were found significantly more often in the abused group than the comparison group. These included surname changes $(30 \% v 2 \%)$, removal from home $(25 \% \quad v 1 \%)$, number of home addresses $(2.8 v 1.4)$, and schools attended (3.4 $v$ 2.2). Other significant findings included further abuse (35\% $v 0 \%$, adverse behaviours $(60 \% v 16 \%)$, educational problems $(24 \% \quad v 5 \%)$, chronic health problems $(54 \% v 36 \%)$, and involvement of mental health services $(32 \% v 1 \%)$.

(Arch Dis Child 2000;83:132-134)
\end{abstract}

Keywords: sexual abuse; follow up

The adverse consequences of childhood sexual abuse are known from a number of retrospective studies. ${ }^{1-5}$ In these studies adults were identified as having been abused in their childhood by their recall or by agency records of the past abuse. These studies reveal that later in life debilitating psychosocial symptoms, educational and occupational difficulties, substance abuse, inappropriate pregnancy, aggression, and criminal activity frequently follow. Further, the abused are prone to become the abusers of the next generation. Emerging evidence links child abuse to adult health problems that arise from social and emotional problems, substance abuse, smoking, and depression. ${ }^{6}$ The effects are thought to result from both the abuse and the often dysfunctional domestic environment in which it occurs. These retrospective studies generally involve participants identified by agency records or mental health services. However, social services or law enforcement agencies are involved in only a minority of cases. ${ }^{7}$ Similarly, studies based on victims who have accessed mental health services reflect the status of only a small fraction of cases in the population.

Long term, prospective studies of victims and controls identified in a variety of ways are in progress and will give a more accurate picture of the proportion of abused children who develop severe, chronic disabilities in the future. ${ }^{8}$ One case control, five year, follow up study involving children identified by medical assessment (positive physical findings and/or determinative interview) generally confirms the findings of the retrospective studies. ${ }^{9}$ The present study was conducted retrospectively in 1997 of a cohort of children whose sexual abuse was diagnosed in 1989.

\section{Methods}

Clinical and immediate management features of 237 children diagnosed in 1989 by consultant community paediatricians as having been sexually abused have been reported previously. ${ }^{10}$ For that study as well as this one, the diagnosis was judged "definite", "when the child provided a clear disclosure or the perpetrator admitted abuse; or where there were gross physical signs of genital or anal trauma without other reasonable explanation; or where there was evidence of infection generally considered to be acquired by sexual contact in virtually every instance, such as gonorrhoea or chlamydia infection. Lesser degrees of certainty included "probable" cases. In these, a summation of findings was sufficiently worrisome to warrant, in the view of the paediatricians, immediate or continued involvement of social agencies for the development of a specific plan of investigation. Examples of such findings would include emotional and behavioural indicators of child sexual abuse (Corwin, 1988, in Wyatt and Powell, eds, Lasting effects of child sexual abuse, Sage, London, pp. 265-8), a partial disclosure statement, less than gross signs of genital or anal injury, and a suspect with access to the child, as for example in the case of a sibling of a child whose abuse is definite."

From this 1989 cohort, 148 children ( 7 years old or less at the time of diagnosis) were selected, as they would be of school age at follow up in 1997. Eighty three current classmates, matched for age and gender, were selected as a comparison group. For both groups information was sought from school health records (SHR) regarding living circumstances, legal status, further abuse, behaviour, educational progress, chronic health problems, and access to mental health services. Hospital records (HR) of the abused children were examined for similar information. Only information from the SHR was used in analyses that compared the two groups. In comparing subsets within the abuse group, information from all records, SHR, and HR were used. Frequencies of recorded characteristics were tested for significant differences between 
Table 1 School health record findings for follow up period, 1990-97

\begin{tabular}{lll}
\hline & $\begin{array}{l}\text { Abused } \\
(n=105)\end{array}$ & $\begin{array}{l}\text { Control } \\
(n=83)\end{array}$ \\
\hline Changed family name & $30 \%$ & $2 \% \dagger$ \\
Removed from home (residence or fostered or adopted) & $25 \%$ & $1 \% \dagger$ \\
Number schools attended, mean (range) & $3.4(1-11)$ & $2.2(1-6) \dagger$ \\
Number home addresses, mean (range) & $2.8(1-13)$ & $1.4(1-5) \dagger$ \\
Further abuse detected after 1990 & $35 \%$ & $0 \% \dagger$ \\
Adverse behaviours, all types & $60 \%$ & $16 \% \dagger$ \\
Aggressive, angry, violent, destructive, or dangerous & $22 \%$ & $1 \% \dagger$ \\
Sexualised & $19 \%$ & $1 \% \dagger$ \\
Educational problems with learning or performance & $24 \%$ & $5 \% \dagger$ \\
"Statemented" & $16 \%$ & $1 \% \dagger$ \\
Chronic health problems (other than wetting or soiling) & $54 \%$ & $36 \% \star$ \\
Physical growth (over or under weight, failure to thrive) & $18 \%$ & $6 \% \star$ \\
Wetting & $20 \%$ & $6 \% \dagger$ \\
Soiling & $10 \%$ & $1 \%{ }^{\star}$ \\
Accessed or referred to mental health consultant & $32 \%$ & $1 \% \dagger$ \\
\hline
\end{tabular}

${ }^{\star} \mathrm{p}=0.01-0.05 ; \mathrm{tp}<0.01$.

abused and controls, and between the abuse group as a whole and subsets thereof. Standard $\chi^{2}$ test was used unless the frequency of a finding was very low, in which case Fisher's exact test was used. To test the differences in numbers of schools attended and numbers of home addresses, a Wilcoxon rank sum test (with ties) was used.

The nature of the records was such that it was not always possible to know the duration of a recorded problem. Therefore the labelling of a child as having a problem implied that the problem was recorded as having been present for at least some of the time between first review in 1990 and follow up review in 1997.

\section{Results}

A total of 105 school health and 95 hospital records were found for the abuse group. Some record was found for 140 of 148 abused children; no record was found for eight. Review of the 1990 analysis of these eight cases revealed no pattern of factors common to the group. For the control group, SHR records were available for 83 of 83 ; hospital records were not sought. Seventy two per cent of the abused and $74 \%$ of the control children were female. Mean age for both groups was 12 years (range 8-15 years). The diagnosis was "definite" for $83(59 \%)$ of the 140 children in the abuse group.

Table 1 shows the proportion of each group for whom information was found in the SHR record that related to selected characteristics. There were significantly more changes in the lives of the abused. These included surname change, and more changes in living address and school attended. Further abuse was documented for $35 \%$ of the abused (from SHR) compared with $0 \%$ for the controls. For the 140 in the abuse group, the HR and/or SHR indicated further abuse of $53(38 \%)$. The types of abuse were sexual in 43 (with additional physical or emotional abuse or neglect for 13) and physical, emotional, or neglect in 10 . Of the 56 identified perpetrators, $73 \%$ were male, $64 \%$ were family members, and $14 \%$ were members of foster families.

A wide variety of adverse behaviours were recorded with substantially increased frequency for the abused as compared to controls $(60 \%$ v 16\%). The difference was greater for the more serious behaviours that involved aggression $(22 \% v 1 \%)$ and sexualised behaviour $(19 \%$ v $1 \%)$.

Educational problems were found much more frequently in the records of the abused compared with the controls $(24 \%$ v 5\%). Sixteen per cent of the abuse group had a Statement of Special Educational Need v 1\% of controls. The current figure for schoolchildren in the local population is around 3\%.

Chronic health problems were generally more common in the abuse group. However, significant differences were found in the types of problems. For example, asthma was noted in the records of $7 \%$ of both abused and controls. Genitourinary complaints (for example, vaginitis, vaginal discharge, genital sores, and dysuria) however were noted for $10 \%$ of the abused and none of the controls. Obesity and failure to thrive were more frequently mentioned in the records of the abuse group, as were wetting $(20 \% v 6 \%)$ and soiling problems $(10 \% v 1 \%)$. The differences in genitourinary signs and symptoms may be spurious because of the likelihood of a greater attention to these matters for the abuse group.

Thirty two per cent of the abused were referred to mental health services compared to only one of the controls. This usually meant referral to a child and adolescent psychiatrist or a clinical psychologist or to teams under their supervision. It was generally not possible to know to what extent these referrals were acted on.

The frequencies of behavioural and educational problems noted for a variety of subsets of the abuse group were compared with the

Table 2 Problem frequency in subsets of abused group

\begin{tabular}{|c|c|c|c|c|}
\hline & \multicolumn{2}{|l|}{ Behaviourf } & \multicolumn{2}{|c|}{ Educationals } \\
\hline & Aggressive & Sexualised & General & Statement \\
\hline Entire group $(n=140)$ & $22 \%$ & $19 \%$ & $26 \%$ & $17 \%$ \\
\hline Removed before follow up period $(n=40)$ & $43 \% \dagger$ & $28 \% \star$ & - & - \\
\hline Removed during follow up period $(\mathrm{n}=36)$ & $50 \% \dagger$ & $33 \% \dagger$ & $47 \% \dagger$ & $31 \% \star$ \\
\hline Further abuse before follow up ${ }^{\star \star}(n=59)$ & $33 \%^{\star}$ & $29 \% \dagger$ & - & - \\
\hline Further abuse in follow up period ${ }^{\star \star}(n=53)$ & $34 \% \dagger$ & $36 \% \dagger$ & $43 \% \dagger$ & $26 \%$ * \\
\hline Family member perpetrator $+\dagger(n=35)$ & $34 \%{ }^{\star}$ & $31 \%$ * & $40 \%$ ^ & $29 \%$ * \\
\hline
\end{tabular}

\#"Aggressive" = aggressive, violent, angry, destructive, or dangerous behaviours.

" "General" = all problems with learning or performance.

" "Removed" = child was removed from home for some period of time either before the follow up period began in 1990, or during the follow up period from 1990 to 1997.

$\star \star$ Abuse recurred after detection in 1989 and was detected prior to the record review in 1990 or later during the follow up period. $+\dagger$ Perpetrator of further abuse in the follow up period was a parent figure.

$\star_{\mathrm{p}}=0.01-0.05 ; \mathrm{tp}<0.01$ to $>0.05$. 
group as a whole. There were significantly more of these problems among children who were removed from their home; who suffered further abuse after initial detection in 1989; and whose further abuser was a parent figure (table 2). No significant differences were found for the following subsets: those whose 1989 diagnosis was "definite" as opposed to "probable"; those categorised in 1990 as having suffered "penetrative" abuse; and those for whom there had been a case conference before the 1990 record review. Children who at the 1990 review had received mental health services were not significantly different from the group as a whole except that more $(35 \%$ v $17 \%$, $\mathrm{p}=0.02$ ) had a statement of special educational need.

It is interesting to note that the frequencies of problems discovered by review of the SHR were essentially unchanged by the addition of HR. This reflects the two way exchange of information between school and hospital doctors and the inclusion of the school health service as a recipient of child protection information.

\section{Discussion}

The identification of children who have been abused and later access to them for follow up information is especially difficult for a variety of reasons. The many professionals (for example, health and medical care providers, social workers, police, and lawyers) who become involved may reach conflicting conclusions as to whether abuse has occurred. Moreover, the child's family will have their own views. All this presents difficulties for accessing follow up information. Child sexual abuse is often considered to be a highly unpleasant and threatening matter whose certainty may be denied by the family and also by authority. Health professionals may be able to enlist the cooperation of the family because their relationship may be perceived to be less threatening when compared to social workers or police officers. They may also be free of many of the constraints that restrict other professionals. For example law enforcement has a need for evidence enabling criminal prosecution, and Social Services need to conclude ongoing risk of abuse or neglect to remain involved. It is hoped that as child abuse becomes increasingly recognised as a major threat to health, that health professionals will apply tried and true tenets of public health and medical practice to implement case finding, intervention, and prevention of this disease.

This is one of only a few follow up studies whose subjects are identified at the outset by paediatricians. Our results are in agreement with other studies that major problems arise in the years following sexual abuse. Moreover, all studies in the burgeoning literature agree that abuse may adversely affect the individual's health over a long period of time. What is less clear are the relative contributions of the abuse itself and the frequently associated family dysfunction. This study does not contribute to the answer to this question. Our main point is that the diagnosis of sexual abuse simply marks the child as likely to have significant problems in the future; we do not assert that the cause of these problems is solely that of the abuse.

We recognise a possible confounder in that our control group, although classmates of the abused children, were not matched for socioeconomic status.

The study showed that the SHR clearly documents the striking chronicle of serious, multifaceted morbidity, affecting children identified by a single medical diagnosis. The challenge now is how to intervene more effectively than in the past. How can health professionals work with others including social services, police, and legal agencies to improve the outlook for this group of children? Evidence is emerging, in support of common sense, that the key person for future healing and wellbeing of the abused child is an able and enabled, committed, non-offending caretaker, that is a mother and/or father figure. ${ }^{11}{ }^{12} \mathrm{~A}$ greater effort to identify and support this person is a place to start.

Presented in part at the spring meeting of the Royal College of Paediatrics and Child Health, 14 April 1999.

1 Sheldrick C. Adult sequelae of child sexual abuse. Br F Psychiatry 1991;158(suppl 10):55-62.

2 Beitchman JH, Zucker KJ, Hood JE, DaCosta GA, Ackman D, Cassavia E. A review of long term effects of child sexual abuse. Child Abuse Negl 1992;16:101-18.

3 Mullen PE, Martin JL, Anderson JC, Romans SE, Herbison GP. The effect of child sexual abuse on social, interpersonal and sexual function in adult life. Br f Psychiatry 1994,165: $35-47$.

4 Briere JN, Elliott DM. Immediate and long term impacts of child sexual abuse. The Future of Children (The David and Lucille Packard Foundation) 1994;4:54-69.

5 McCauley J, Kern DE, Kolodner K, et al. Clinical characteristics of women with a history of childhood abuse. characteristics of women

6 Felitti VJ, Anda RF, Nordenberg D, et al. Relationship of childhood abuse and household dysfunction to many of the leading causes of death in adults; the adverse childhood experience (ACE) study. Am f Prev Med 1998;14:245-58.

7 US Department of Health and Human Services. The third national incidence study of child abuse and neglect. Washington, DC: US Department of Health and Human Services, 1996.

8 Runyan DK, Curtis PA, Hunter WM, et al. LONGSCAN: a consortium of longitudinal studies of maltreatment and the ife course of children. Agrression and Violent Behavior 1998;3:257-85

9 Swanston HY, Tebbutt JS, O'Toole BI, Oates RK. Sexually abused children 5 years after presentation: a case control study. Pediatrics 1997;100:600-8.

10 Frothingham TE, Barnett RAM, Hobbs CJ, Wynne JM. Child sexual abuse in Leeds before and after Cleveland. Child sexual abuse in Leeds before
Child Abuse Review 1993;2:23-34.

11 Everson MD, Hunter WM, Runyan DK, et al. Maternal support following disclosure of incest. Am f Orthopsychiatry 1989;59:197-207

12 Cohen JA, Mannarino AP. Factors that mediate treatment outcome of sexually abused preschool children: six and twelve month follow-up. 7 Am Acad Child Adolesc Psychiatry $1998 ; 37: 44-51$ 